\title{
The Application Research of Project Management Maturity Model of Real Estate Development Enterprise based on BIM Technology
}

\author{
WAN YUN ${ }^{* 1, a}$, MA YUHAN $^{1, \mathrm{~b}}, \mathrm{ZHOU}$ WANQING ${ }^{1, \mathrm{c}}$ \\ ${ }^{1}$ Civil Engineering And Architecture Jiangxi Science \& Technology Normal University Nanchang, Jiangxi, China
}

\begin{abstract}
This paper takes the project management of real estate development enterprises as the research object. The five elements of progress, quality, cost, safety and risk are selected to establish a maturity evaluation index system. Aiming at the target layer, element layer and index layer based on the application of BIM technology, this paper constructs the corresponding maturity model, and conducts case analysis on the enterprise project management level before and after the application of BIM technology to verify the application effect of BIM technology. The research results provide important management theories, standards and tools for improving the application effect of BIM technology.
\end{abstract}

\section{Introduction}

As a capital-intensive real estate industry, real estate development enterprises pay attention to product quality, development efficiency, cost control and so on to achieve high premium and fast turnover. However at the same time, in project management, there are common problems of cooperation among the owners, design units, consulting units, contractors, subcontractors, and supervision units. For example, unclear powers and responsibilities, poor management and coordination, and mutual shirk of responsibilities. These phenomena can lead to frequent quality accidents, construction delays, cost overruns and other problems[1]. This paper establishes a maturity model for the project management of real estate development enterprises based on BIM technology in order to verify the application effect of BIM technology.

\section{The application of BIM technology in project management of real estate development enterprises}

\subsection{Scheme comparison and selection stage}

The building model information system based on BIM technology can provide the content of geographic information and engineering geology, and make visual and concrete display to help decision makers formulate reasonable construction objectives. It can form a multilevel and structured database containing various kinds of relevant information such as engineering cost information and engineering material information, so that decision makers can guarantee the maximum return and rationalize the investment in the stage of scheme comparison and selection.

\subsection{Design stage}

The three-dimensional expression of BIM technology image enables decision makers to switch scenes and roam in the architectural model, veritably feel the construction process and visually experience the design results. It enables managers and decision makers with insufficient professional and technical background to realize design pre-control, and the major design problems that may occur can be controlled in advance [2].

\subsection{Bidding stage}

BIM technology can demonstrate a more accurate scope of project bidding and produce more accurate bidding documents to effectively control project investment. By using BIM to obtain more detailed data of sub-project and unit project, it can estimate the contents that may be omitted in the bidding stage in the early stage and which data for the project investment has the greatest impact. So that decision makers can form relatively clear cognitions of cost control in the early stage, grasp the main contradictions and control project from the overall perspectives.

\subsection{Construction stage}

Using BIM model can timely optimize and adjust design problems of architecture, structure, electromechanical and other majors. With the help of BIM three-dimensional model, collision detection of engineering projects is implemented to timely find the problems existing in the design drawings, which can not only buy the time for the adjustment but also optimization scheme and reduce the cost. Furthermore, through simulation construction, the

\footnotetext{
a*e-mail :1660540015@qq.com be-mail:616660718@qq.com ce-mail:2868860648@qq.com
} 
enterprise management team can check whether each progress node is reasonable and urge the construction unit to reasonably allocate the construction process of crosswork according to the simulation results, so as to develop a reasonable construction schedule. BIM technology adopts four-dimensional (three-dimensional space and time dimension) virtual engineering implementation, so as to complete the progress management and fully improve the accuracy of the schedule plan. In terms of security, the BIM model establishes a surveillance system by connecting cameras to discover potential security risks. For example, BIM model is connected with fire-fighting facilities. When a fire occurs, BIM model automatically alarm, locates and sends the three-dimensional location and room of the fire through the LAN, and displays safe evacuation passage on the big screen, etc. In case of emergency, it can quickly respond and provide information data, which is especially important for protecting the safety of life and property.

\section{Building of BIM technology maturity model}

\subsection{Division project management maturity level of real estate development enterprises based on BIM technology}

BIM maturity model is used to measure the maturity standard of certain aspects of project management after the application of BIM technology. Target layer, element layer and indicator layer are the main structure of project management maturity model[3]. The element layer covers all aspects of the project organization and management ability, and the elements of the element layer are expressed through the indicator layer, so as to make a comprehensive judgment on the project management ability.

In this paper, the project management level is divided into five levels: preliminary stage, development stage, improvement stage, maturity stage and optimization stage. The scoring criteria are 1 point, 2 points, 3 points, 4 , points and 5 points respectively. The is shown in Figure 1.

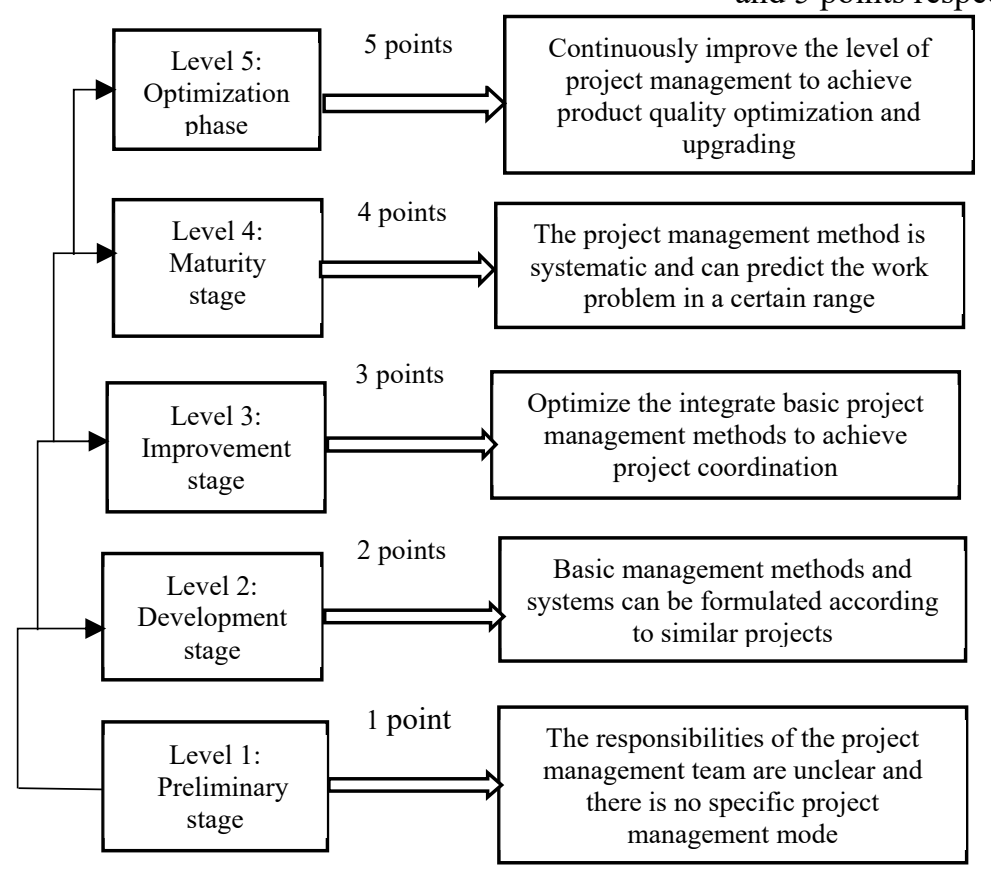

Figure 1 The maturity level of real estate development project management based on BIM technology

\subsection{Establishing project management maturity evaluation index system of real estate development enterprises based on BIM technology}

In view of the application of BIM technology in project management of real estate development enterprises, the five elements of progress, quality, cost, safety and risk are selected to establish a maturity evaluation index system. This is shown in Table 1. 
Table1. Evaluation index system of project management maturity of real estate development enterprises based on BIM technology

\begin{tabular}{|c|c|c|}
\hline Maturity level & Element layer & Index layer \\
\hline \multirow{2}{*}{$\begin{array}{c}\text { Preliminary stage } \\
\downarrow \downarrow\end{array}$} & \multirow[t]{3}{*}{ Progress management $\left(\mathrm{B}_{1}\right)$} & Total progress deviation $\left(\mathrm{B}_{11}\right)$ \\
\hline & & Preparation of progress plan $\left(\mathrm{B}_{12}\right)$ \\
\hline \multirow{2}{*}{$\begin{array}{c}\text { Development stage } \\
\downarrow\end{array}$} & & Control the actual progress $\left(\mathrm{B}_{13}\right)$ \\
\hline & \multirow[t]{3}{*}{ Quality management $\left(\mathrm{B}_{2}\right)$} & Completion of relevant technical documents $\left(\mathrm{B}_{21}\right)$ \\
\hline \multirow{2}{*}{$\begin{array}{l}\text { Improvement stage } \\
\qquad \downarrow\end{array}$} & & On-site quality inspection $\left(\mathrm{B}_{22}\right)$ \\
\hline & & The soundness of the quality management system $\left(\mathrm{B}_{23}\right)$ \\
\hline \multirow{11}{*}{$\begin{array}{l}\text { Maturity stage } \\
\qquad \downarrow \\
\text { Optimization phase }\end{array}$} & \multirow[t]{4}{*}{ Cost management $\left(\mathrm{B}_{3}\right)$} & Project resource planning $\left(\mathrm{B}_{31}\right)$ \\
\hline & & Rework loss expense(B32) \\
\hline & & Project price management $\left(\mathrm{B}_{33}\right)$ \\
\hline & & The degree of engineering change $\left(\mathrm{B}_{34}\right)$ \\
\hline & \multirow[t]{3}{*}{ Safety management $\left(\mathrm{B}_{4}\right)$} & The soundness of the safety management system $\left(\mathrm{B}_{41}\right)$ \\
\hline & & $\begin{array}{l}\text { Inspection of construction equipment and hazardous } \\
\text { substances (B42) }\end{array}$ \\
\hline & & Handling of construction accidents (B43) \\
\hline & \multirow[t]{4}{*}{ Risk management (B5) } & Risk management plan $\left(\mathrm{B}_{51}\right)$ \\
\hline & & Risk identification and analysis ( $\left.\mathrm{B}_{52}\right)$ \\
\hline & & Risk Response Plan (B53) \\
\hline & & Risk control measures (B54) \\
\hline
\end{tabular}

\subsection{Maturity evaluation model based on BIM technology}

The fuzzy comprehensive evaluation method is used to evaluate the maturity evaluation index quantitatively. The basic steps are as follows:

\subsubsection{Determine the factor set}

The factor set $B=\left[B_{1}, B_{2}, \ldots, B_{n}\right]$, indicating that the rating object has $\mathrm{n}$ evaluation factors. The element layer is refined to obtain the index layer. The factor set is composed of the element layer and the index layer.

\subsubsection{Determine the comment set}

The evaluation results of $\mathrm{N}$ indicators were obtained through expert scoring.

\subsubsection{Determine the weight vector of the evaluation index}

Analytic Hierarchy Process (AHP) is used to determine the weight of evaluation factors.

\subsubsection{Single-factor fuzzy evaluation}

From the weight vector $A_{i}$ of the index layer and the judgment matrix $R_{i}$ of the factor layer, the discriminant vector $B_{i}$ of the evaluated object is obtained as $B_{i} \times R_{i}$. The evaluation results of each factor in the element layer were obtained from the discriminant vector $\mathrm{B}_{\mathrm{i}}$ and the scoring indicator $\mathrm{C}^{\mathrm{T}}, \mathrm{U}_{\mathrm{i}}=\mathrm{B}_{\mathrm{i}} \times \mathrm{C}^{\mathrm{T}}$.

\subsubsection{Multi-factor fuzzy comprehensive evaluation}

The comprehensive evaluation results of the rating object are obtained by the vector composed of the evaluation result $\mathrm{U}_{\mathrm{i}}$ of the element layer and the weight vector $\mathrm{W}$ of the element layer, which is $\mathrm{U}=\left[\mathrm{U}_{1}, \mathrm{U}_{2}, \ldots, \mathrm{U}_{\mathrm{n}}\right] \times \mathrm{W}^{\mathrm{T}}$.

\section{Case analysis}

In this paper, a real estate development project is selected as the verification object.This paper uses the established maturity model to evaluate and analyze the project management process of real estate enterprises.

\subsection{Determine the maturity model index weight}

According to the logical structure of the maturity model, pairwise comparison is made between each element of the element layer and each element of the index layer based on its importance to the target layer and each element of the index layer based on its importance to the subordinate elements, so as to obtain the paired comparison matrix of the element layer and the index layer [4].

Eight experts from the construction industry in Jiangxi Province were invited to scrod each indicator and take the average value as the final evaluation result. The weight of each indicator is calculated by paired comparison matrix, the maximum eigenvalue and eigenvector of the matrix are determined, and the weight vector can be obtained by 
normalizing the eigenvector. The index weights of the maturity model are shown in Table 2.

Table2. Maturity model index weights

\begin{tabular}{|c|c|c|c|}
\hline Maturity level & Weight & Index layer & Weight \\
\hline \multirow{2}{*}{$\begin{array}{c}\text { Preliminary stage } \\
\downarrow\end{array}$} & \multirow[t]{3}{*}{0.0666} & Total progress deviation $\left(\mathrm{B}_{11}\right)$ & 0.4721 \\
\hline & & Preparation of progress plan $\left(\mathrm{B}_{12}\right)$ & 0.1298 \\
\hline \multirow{2}{*}{$\begin{array}{c}\text { Development stage } \\
\qquad \downarrow\end{array}$} & & Control the actual progress $\left(\mathrm{B}_{13}\right)$ & 0.3981 \\
\hline & \multirow[t]{3}{*}{0.4181} & Completion of relevant technical documents $\left(B_{21}\right)$ & 0.4515 \\
\hline \multirow{13}{*}{$\begin{array}{c}\downarrow \\
\text { Maturity stage } \\
\downarrow \\
\text { Optimization phase }\end{array}$} & & On-site quality inspection ( $\left.\mathrm{B}_{22}\right)$ & 0.2921 \\
\hline & & The soundness of the quality management system $\left(\mathrm{B}_{23}\right)$ & 0.2564 \\
\hline & \multirow[t]{4}{*}{0.0953} & Project resource planning $\left(\mathrm{B}_{31}\right)$ & 0.3223 \\
\hline & & Rework loss expense( $\left(\mathrm{B}_{32}\right)$ & 0.2157 \\
\hline & & Project price management $\left(\mathrm{B}_{33}\right)$ & 0.2338 \\
\hline & & The degree of engineering change $\left(\mathrm{B}_{34}\right)$ & 0.2282 \\
\hline & \multirow[t]{3}{*}{0.1178} & The soundness of the safety management system (B 41 ) & 0.3152 \\
\hline & & $\begin{array}{l}\text { Inspection of construction equipment and hazardous } \\
\text { substances (B42) }\end{array}$ & 0.3319 \\
\hline & & Handling of construction accidents (B43) & 0.3529 \\
\hline & \multirow[t]{4}{*}{0.3022} & Risk management plan $\left(\mathrm{B}_{51}\right)$ & 0.2412 \\
\hline & & Risk identification and analysis (B52) & 0.2174 \\
\hline & & Risk Response Plan (B53) & 0.3351 \\
\hline & & Risk control measures (B54) & 0.2063 \\
\hline
\end{tabular}

\subsection{Single-factor evaluation}

According to the project management team's scores on the project management level before and after the use of BIM technology, and the single-factor evaluation is carried out[5].

$\mathrm{B}_{1}$ (Progress management $)=\left[\mathrm{B}_{11}, \mathrm{~B}_{12}, \mathrm{~B}_{13}\right]=[$ Total progress deviation, Preparation of progress plan, Control the actual progress]

Fuzzy judgment matrix r1 (Before)

$r_{1}=\left[\begin{array}{llllc}0 & 0.1 & 0.2 & 0.4 & 0.1 \\ 0 & 0.3 & 0.4 & 0.2 & 0 \\ 0 & 0.2 & 0.3 & 0.5 & 0.2\end{array}\right]$

Fuzzy judgment matrix R1 (After)

$$
\mathrm{R}_{1}=\left[\begin{array}{lllll}
0 & 0.2 & 0.3 & 0.6 & 0.2 \\
0 & 0.3 & 0.4 & 0.1 & 0.1 \\
0 & 0.2 & 0.3 & 0.4 & 0.2
\end{array}\right]
$$

The weight set: $A_{1}=[0.4721,0.1298,0.3981]$;

The judgment vector:

$\mathrm{b}_{1}=\mathrm{A}_{1} \times \mathrm{r}_{1}=[0,0.166,0.266,0.414,0.127]$;

$\mathrm{B}_{1}=\mathrm{A}_{1} \times \mathrm{R}_{1}=[0,0.213,0.313,0.455,0.187]$;

Single-factor evaluation:

$\mathrm{u}_{1}=\mathrm{b}_{1} \times \mathrm{C}^{\mathrm{T}}$

$=[0,0.166,0.266,0.414,0.127] \times[1,2,3,4,5]^{\mathrm{T}}=3.421$;

$\mathrm{U}_{1}=\mathrm{B}_{1} \times \mathrm{C}^{\mathrm{T}}=4.120$.

Similarly, the evaluation values of other factors in the factor set can be derived.

$\mathrm{u}_{2}=3.405 ; \mathrm{U}_{2}=4.235 ; \mathrm{u}_{3}=3.074 ; \mathrm{U}_{3}=4.113 ; \mathrm{u}_{4}=3.733 ;$ $\mathrm{U}_{4}=4.038 ; \mathrm{u}_{5}=3.388 ; \mathrm{U}_{5}=3.917$.

Single-factor evaluation: After the project management team in the use of BIM technology, the maturity score of progress management increased from 3.421 points to 4.120 points, quality management increased from 3.405 points to 4.235 points, and cost management from 3.047 points rose to 4.113 points. These four aspects of management level have risen from the improvement stage to the mature stage and resulted in qualitative change. Cost management maturity score increased the most, indicating that the use of BIM technology can greatly reduce the cost of project management. Although the risk management maturity score rose from 3.388 points to 3.917 points, there was not produce a qualitative change, indicating that the following possibilities: First, the project management team is not skilled enough in the use of BIM technology in risk management; Second, BIM technology has little impact on the improvement of risk management capabilities.

\subsection{Multi-factor comprehensive evaluation}

Element layer weight vector:

$\mathrm{W}=[0.0666,0.4181,0.0953,0.1178,0.3022]$

$\mathrm{u}=\left[\mathrm{u}_{1}, \mathrm{u}_{2}, \mathrm{u}_{3}, \mathrm{u}_{4}, \mathrm{u}_{5}\right] \times \mathrm{W}^{\mathrm{T}=3.408}$;

$\mathrm{U}=\left[\mathrm{U}_{1}, \mathrm{U}_{2}, \mathrm{U}_{3}, \mathrm{U}_{4}, \mathrm{U}_{5}\right] \times \mathrm{W}^{\mathrm{T}}=4.096$.

Comprehensive evaluation: After the project in the use of BIM technology, integrated project management level by 3.408 points to 4.096 points, from the improvement stage to the mature stage, resulting in qualitative change, which indicates the team has a mature project management method, sets clear goals, and in a controlled range can predict the problems in the management. 


\section{Conclusion}

To sum up, the project management maturity model is an effective tool to study the application effect of BIM technology. Through the comparison and evaluation before and after the application of BIM technology, the changes brought by the application of BIM technology to various aspects of project management of real estate development enterprises can be clarified. In enterprise project management, the management team should pay more attention to BIM technology and actively explore new ideas for BIM technology application in order to achieve the maximum benefit of project management.

\section{References}

1. Qi Shuang, Kuang Jiazhi. Project management implementation status analysis BIM solutions. [J] Information Technology in Civil and Architectural engineering. 2013 (5):26-33.

2. Ye Shenghua. The application status and countermeasure of BIM technology in owner-side project management. [J] Housing and Real Estate. 2019(5):117-123.

3. Lu Yijun, Wang Xiaoni, Sun Qian. Construction of maturity evaluation model for bridge maintenance management based on analytic hierarchy process. Fujian Building Materials, 2020(5) : 4-6.

4. Wang Wenyin. Study on outsourcing/outsourcing supplier management maturity model based on mould and comprehensive evaluation $[\mathrm{J}]$. Modern business, 2020(7) : 99-100.

5. Ge Bin. Research on the application of BIM technology in owner-side project management. [D] Chongqing Jiaotong university, 2015. 